\title{
Harmonious Tourism Environment and Tourists Perception: An Empirical Study of Mountain-Type World Cultural Heritage Sites in China
}

\author{
Zhiyong Fan*, Sheng Zhong, Wei Zhang \\ School of Economics and Management, Wuhan University, Wuhan, China. \\ Email: *fanzhiyong68@tom.com, \{fyzhongsheng, zhang3157\}@163.com
}

Received December $31^{\text {st }}$, 2011; revised February $13^{\text {th }}$, 2012; accepted February $19^{\text {th }}, 2012$

\begin{abstract}
This study tested the structural equation model between harmonious tourism environment perception and tourists' loyalty. In this paper, a model is erected to indicate the relationship between harmonious tourism environment perception and tourists' loyalty. With 377 valid questionnaires from 8 mountain-type world cultural heritage sites in China, the author tested the model by SPSS and AMOS. It was found that the perception of natural ecosystem was the most influential factor affecting tourists' entire environment perception, social relations system was the second place and cultural ecosystem was the third place. The entire harmonious tourism environment perception also greatly determines tourists' loyalty. At last, some suggestions were given to make tourism destination develop sustainably based on this study.
\end{abstract}

Keywords: Harmonious Tourism Environment; Tourist Perception; World Cultural Heritage

\section{Introduction}

Tourist perception is the tourist's comprehensive perception on the attractions, environment, products and services in tourism destination. Tourist perception and behavior is the hot spot in tourism research, and the contemporary literatures mainly focus on the theory model of "quality-value-satisfaction-loyalty", which has been fully or partly tested through different cases, variables in many studies [1-5]. However, there is still lacking the empirical research on the tourist's all-round perception on the destination's environment, as well as the relationship among perception, satisfaction and loyalty.

Tourism environment is the foundation of all the tourism attractions, products and activities. In the current process of tourism development, harmonious tourism environment represents the future of tourism environment construction. As a necessary route to sustainable development in destination, harmonious tourism environment is a harmonious state of natural ecosystem, cultural ecosystem and social relation system in tourism destination under the direction of scientific development perspective [6]. Till the end of 2009, there has been 8 mountain-type world cultural heritage sites (hereinafter "8 mountains"), including Mount Taishan, Mount Huangshan, Mount Wudang, Mount Lushan, Mount Emei, Mount Wuyi, Mount Qingcheng and Mount Wutai, all of which also

\footnotetext{
*Corresponding author.
}

sever as the most famous tourism destinations in China. Zhang et al. [7] discussed the fundamental theory model of the tourism harmonious environment's construction in mountain-type cultural heritages. Based on Zhang's research, this paper takes an empirical approach to study the relationship between the perception of tourism harmonious environment and tourists' loyalty from the perspective of tourist perception.

\section{Perception of Harmonious Tourism Environment}

\subsection{Harmonious Relationship in Natural Ecosystem}

Natural ecosystem is the foundation of all the tourism actions in mountain-type world cultural heritages and serves as a basic component in harmonious tourism environment. In China, all the mountain-type cultural heritage sites boast unique geographical features, beautiful natural sceneries and abundant biological resources. There are 4 mountains in "8 mountains" are both cultural and natural heritages (Mount Taishan, Mount Huangshan, Mount Wuyi and Mount Emei), as well as 2 cultural landscape heritages which represent the perfect combination of human and nature (Mount Lushan and Mount Wutai). Meanwhile, because of the features of instability, sensibility and fragility, mountain-type heritages are very 
vulnerable under the condition of the mass tourists' pouring. So, this study takes 7 variables, including climate, geology, water, atmosphere, sound, biology and sanitation, as the measuring objects to scale the tourists' perception on the harmonious relationships in natural ecosystem, at the same time provides basis for the natural environment's management and monitoring in tourism destinations.

\subsection{Harmonious Relationship in Cultural Ecosystem}

Culture plays an essential role in world cultural heritage sites, and cultural ecosystem-the harmonious relationship between human and cultural heritage is the core in mountain-type cultural heritage's environment. The 8 mountain-type cultural heritages in China play a very important role in Chinese culture history. For example, Mount Emei, Mount Qingcheng, Mount Wudang and Mount Wutai are sacred mountains in Buddhism or Taoism; Mount Taishan also served as a sacred site for ancient Chinese emperors to sacrifice to heaven; Mount Wuyi is the origin of Zhuxi culture, known as one subsidiary of Confucianism; Mount Huangshan and Mount Lushan bear many thoughts in Chinese traditional aesthetics. Therefore, the 6 indicators in this part are not only antiquities, architectural complexes, relics and cultural landscapes, which represent the authenticity and integrity of cultural heritage, but also the inheriting state of cultural traditions, as well as the coordination between tourism facilities and environment. By measuring these indicators, this part aims to observe the tourists' perception on the harmonious relationship of human and cultural heritage, and help to the cultural heritage's protection and cultural atmosphere.

\subsection{Harmonious Relationship in Social Relation System}

Natural and cultural environment cannot be isolated in cultural heritage sites, especially in the process of tourism developing, because they are enormously affected by all kinds of stakeholders, such as the attitudes of local residents, the relationship between residents and operators, the cultural shock and interference taken by tourists. So, the social relation system-harmonious relationship among stakeholders also should be regarded as an important part in the destination's harmonious environment. It is significant to research the relationships in or among the tourists, residents and operators, because since 1970s, with millions tourists pouring in annually, tourism developed in an incredible speed in the "8 mountains" in China. Therefore, from the perspective of tourists, this paper takes the relation between residents and operators, relation between hosts and guests, tourism services, tourism commodities, public security and tourists' density, totally 6 indicators, to watch the harmonious condition of social relation system, so as to help refine the management institution and construct harmonious relations among stakeholders.

\subsection{Entire Perception on Harmonious Tourism Environment}

The perception of harmonious tourism environment is the tourists' entire recognition on destination's environment, constituted by two aspects, one is the satisfaction as well as the other is the participation degree in environmental construction. So, two items about this part were put forward in the questionnaire are: "I am satisfied with the tourism environment" and "I will contribute my effort to tourism environment”, respectively represent the tourists' satisfaction and participation.

\subsection{Loyalty}

A competitive tourist destination is that one can satisfy tourists, and attract more tourists by means of present tourists' revisit and recommendation, so as to attain a stable market. The conception of tourist loyalty stems from customer loyalty, as Opperman [8] argued that, the tourist loyalty on one destination can be comprehended in two aspects, one is the behavior, loyalty is closely related with the frequency of revisit; the other is the manner, loyalty is presented in tourists' revisit intention and recommendation intention. Thus, two items in this part are: "I will come here again" and "I will recommend others to travel here", respectively represent the revisit intention and recommendation intention.

\subsection{Theoretical Model and Hypothesis}

Based on the analysis of harmonious relationships in natural ecosystem, cultural ecosystem, social relation system, entire perception on harmonious environment and tourists' loyalty, this paper erects a harmonious environment perception theoretical model, including 5 structure variables and 23 items, to measure the effect of natural ecosystem, cultural ecosystem and social relation system to entire perception of harmonious tourism environment, as well as entire perception to tourists' loyalty respectively, as shown in Figure 1. At the same time, there are 4 hypotheses in this paper:

H1: Natural ecosystem directly affects the entire perception of harmonious tourism environment.

H2: Cultural ecosystem directly affects the entire perception of harmonious tourism environment.

H3: Social relation system directly affects the entire perception of harmonious tourism environment. 




Figure 1. Harmonious tourism environment perception model.

H4: Entire perception of harmonious tourism environment directly affects the tourists' loyalty.

\section{Research Methods and Questionnaire}

\subsection{Research Methods}

This research utilizes SPSS 13.0 as the tool to conduct descriptive analysis, factor analysis and reliability analysis. Then AMOS 7.0 is used to depict the structural equation model (SEM) of the harmonious tourism environment perception theoretical model, as well as calculate and test the path coefficients. SEM now is broadly used in the realms of psychology, pedagogy, statistics and marketing, and is also more and more applied in tourism research. SEM can test and estimate the casual relations in theoretical model, so it is available in this research.

\subsection{Questionnaire Design}

The questionnaire is divided into two parts, part one is the 23 items or questions, which are measured based on a five point Likert scale ranging from 1 to 5 , where $1=$ Strongly disagree; 3 = Neutral; 5 = Strongly agree. Part two is the sample's demographic characters, including gender, age, occupation, education level, as well as tourism pattern. The online questionnaire also includes two questions of timing and visiting time. Timing is the time from responder begins the questionnaire to complete it and is automatically conducted by computer. Visiting time is when the responder's last visiting to "8 mountains".

\subsection{Survey Process}

The authors have made lots of investigations in "8 mountains" before this study, visited Mount Wudang in June 2008, Mount Lushan in October 2008, Mount Taishan in June 2009, Mount Emei and Qingcheng in October 2009, Mount Wuyi in November 2009, Mount Huangshan in April 2010. In every investigation, the authors not only observed the tourism environment in "8 mountains", but also made a lot of questionnaire surveys and interviews on tourists and local residents, which served as the original data for this study.

The questionnaire survey for this paper is divided into two parts, one is onsite and the other is online. The onsite survey was carried out in Mount Taishan in June 2009, 158 questionnaires were taken back and 154 were identified valid, the percent of validity is $97.5 \%$. With the help of the online survey tool "questionnaire star" (www.sojump.com), the online questionnaires were published from November 20 to December 20, 2009. With the average filling time is 277 seconds, 465 persons who formerly visited "8 mountains" answered the questionnaires and 223 were identified valid after deleting the visiting time before 2008, the percent of validity is $50.1 \%$. For this paper, the authors totally took back 623 questionnaires, valid is 377 , and the total validity percent is $60.5 \%$

With the fast growing of internet, online questionnaire survey is also becoming more and more popular. The responders can get enough time to complete the questionnaire online; at the same time every question is required to answer, so as to avoid the hurry answering and miss answering, both of which frequently occurred in onsite questionnaires. Fang et al. [9] proved the validity of online questionnaire through an empirical research, and in tourism research realm, Chen and Huang [10] studied the influencing factors of tourists revisit decision.

\section{Research Results}

\subsection{Demographic Analysis}

Demographic characteristics are calculated from the samples (see Table 1), and female is more than male, most people's age are between 15 - 34 (56.3\%), the majority of the samples $(78.5 \%)$ have the education level of the college, students are the most frequent occupation (48.05) as well as travel with friends is the most popular tourism pattern (41.1\%).

\subsection{Factor Analysis}

With the help of SPSS 13.0, we can see the descriptive analysis results of 23 items in Table 2, with KMO = 0.939 , Bartlett test $p=0.000$. After rotation, 19 items about tourism environment were deduced into 3 factors, together accounting for $63.244 \%$ of the total variance, and all the items' factor loading are more than 0.50 . The scores of 2 items in harmonious tourism environment perception, respectively about total satisfaction and participation intention, are relatively high, which shows the tourists' high recognition on tourism environment. In the 2 items of tourists' loyalty, tourists' recommendation inten- 
Table 1. Sample characteristics.

\begin{tabular}{|c|c|c|}
\hline Items & Options & Frequency \\
\hline \multirow{2}{*}{ Gender } & Male & $39.8 \%$ \\
\hline & Female & $60.2 \%$ \\
\hline \multirow{6}{*}{ Age } & Less than 14 & $0.5 \%$ \\
\hline & $15-24$ & $56.5 \%$ \\
\hline & $25-34$ & $27.3 \%$ \\
\hline & $35-44$ & $10.6 \%$ \\
\hline & $45-54$ & $3.7 \%$ \\
\hline & More than 55 & $0.8 \%$ \\
\hline \multirow{4}{*}{$\begin{array}{l}\text { Education } \\
\text { level }\end{array}$} & Junior high school or below & $0.8 \%$ \\
\hline & Senior high school & $6.9 \%$ \\
\hline & Undergraduate & $78.5 \%$ \\
\hline & Postgraduate & $13.8 \%$ \\
\hline \multirow{7}{*}{ Occupation } & Enterprise staff & $21.5 \%$ \\
\hline & Individual business & $5.6 \%$ \\
\hline & Peasants & $0.5 \%$ \\
\hline & Students & $48.0 \%$ \\
\hline & Liberal professions & $6.4 \%$ \\
\hline & Government staff & $11.7 \%$ \\
\hline & Others & $6.4 \%$ \\
\hline \multirow{6}{*}{ Tourism pattern } & Join travel agency & $17.0 \%$ \\
\hline & Cooperation arrange & $6.9 \%$ \\
\hline & Conference & $4.2 \%$ \\
\hline & With friends & $41.1 \%$ \\
\hline & With family & $15.9 \%$ \\
\hline & individual & $14.9 \%$ \\
\hline
\end{tabular}

tion is higher than revisit intention, so the tourists are more likely to recommend others than travel there once more after one visit to " 8 mountains". The average score of 7 items in natural ecosystem are the highest in 5 structure variables, only the sanitation is relatively low. Regarding the 6 items in cultural ecosystem, the scores of antiquities, architectural complexes, relics and landscapes are higher than 4 , yet the scores of inheriting state of cultural traditions and coordination between tourism facilities and environment are less than 4. However, all the scores of 6 items in social relation system are lower than 4, especially tourism commodities' score is the lowest 3.29, which indicates the tourists' low satisfaction on social relation system. Finally, with the reliabilities ( $\alpha$ Cronbach) of 3 factors more than 0.80 , so it is appropriate for structural equation model (SEM) analysis in this study.
Table 2. Results of descriptive analysis.

\begin{tabular}{|c|c|c|c|c|}
\hline Items & Loadings & Reliability & Mean & S.D. \\
\hline \multicolumn{5}{|l|}{ Natural ecosystem } \\
\hline X1 Climate & 0.823 & & 4.11 & 0.77 \\
\hline X2 Geology & 0.809 & & 4.11 & 0.77 \\
\hline X3 Water & 0.781 & & 3.95 & 0.90 \\
\hline X4 Atmosphere & 0.646 & 0.868 & 4.02 & 0.81 \\
\hline X5 Sound & 0.636 & & 3.97 & 0.83 \\
\hline X6 Biology diversity & 0.634 & & 3.93 & 0.84 \\
\hline X7 Sanitation & 0.601 & & 3.77 & 0.97 \\
\hline \multicolumn{5}{|l|}{ Cultural ecosystem } \\
\hline X8 Antiquities & 0.842 & & 4.05 & 0.79 \\
\hline X9 Architectural complexes & 0.830 & & 4.03 & 0.78 \\
\hline X10 Relics & 0.787 & & 4.09 & 0.76 \\
\hline X11Cultural landscapes & 0.787 & 0.852 & 4.05 & 0.82 \\
\hline $\begin{array}{l}\text { X12 Inheriting state of } \\
\text { cultural traditions }\end{array}$ & 0.703 & & 3.79 & 0.86 \\
\hline $\begin{array}{l}\text { X13 Coordination between } \\
\text { tourism facilities and } \\
\text { environment }\end{array}$ & 0.540 & & 3.74 & 0.83 \\
\hline \multicolumn{5}{|l|}{ Social relation system } \\
\hline $\begin{array}{l}\text { X14 Relation between } \\
\text { residents and operators }\end{array}$ & 0.826 & & 3.68 & 0.91 \\
\hline $\begin{array}{l}\text { X15 Relation between hosts } \\
\text { and guests }\end{array}$ & 0.717 & & 3.62 & 0.92 \\
\hline X16 Tourism services & 0.704 & 0.887 & 3.57 & 0.96 \\
\hline X17 Tourism commodities & 0.694 & & 3.29 & 1.09 \\
\hline X18 Public security & 0.651 & & 3.80 & 0.83 \\
\hline X19 Tourists’ density & 0.534 & & 3.48 & 0.99 \\
\hline \multicolumn{5}{|l|}{$\begin{array}{l}\text { Harmonious tourism } \\
\text { environment perception }\end{array}$} \\
\hline $\begin{array}{l}\text { Y1 Tourists' satisfaction on } \\
\text { environment }\end{array}$ & & & 4.03 & 0.73 \\
\hline $\begin{array}{l}\text { Y2 Tourists’ participation } \\
\text { intention to environment } \\
\text { protection }\end{array}$ & & & 3.84 & 0.96 \\
\hline \multicolumn{5}{|l|}{ Tourists' loyalty } \\
\hline Y3 Revisit intention & & & 3.75 & 0.94 \\
\hline $\begin{array}{l}\text { Y4 Recommendation } \\
\text { intention }\end{array}$ & & & 4.02 & 0.82 \\
\hline
\end{tabular}

\subsection{Structure Equation Model (SEM) Analysis}

With the help of AMOS 7.0, Figure 2 shows the estimated path coefficients of the harmonious tourism environment perception model and all of the 4 hypotheses are accepted.

1) Natural ecosystem significantly affects the entire perception of harmonious tourism environment $(0.32, p=$ $0.000)$. As the foundation of cultural heritage and tourism activities, natural ecosystem plays the most important role in tourists' perception on tourism environment. 


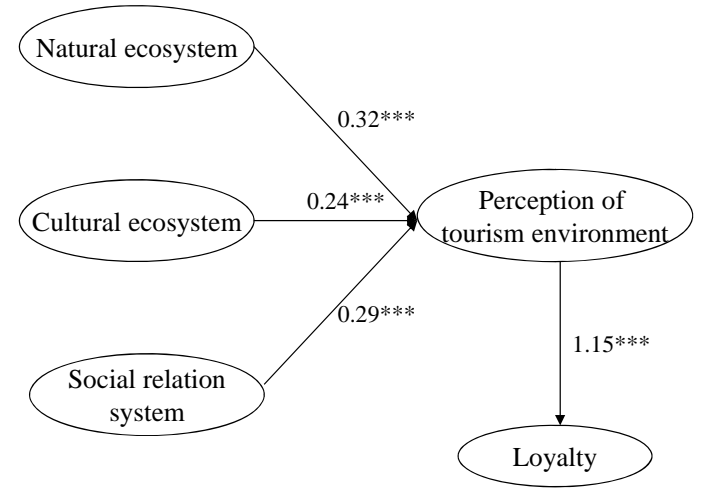

Figure 2. Structural equation model test. (Notes: ${ }^{* * *}$ indicates $p<0.001$, two-tailed test).

From the descriptive analysis shown in Table 2, tourists are relatively satisfied with the natural ecosystem. So, it is very necessary to sustain the harmony in natural ecosystem, as well as enhance the environment sanitation and monitoring.

2) Cultural ecosystem significantly affects the entire perception of harmonious tourism environment $(0.24, p=$ 0.000 ). The surveys also show that tourists are satisfied with the conservation of cultural heritage, however the inheriting state of cultural traditions and the coordination of tourism facilities and environment are not very well in tourists' eyes. The path efficient between cultural ecosystem and the perception of tourism environment is relatively small, which also indicates that the cultural propagation function of cultural heritages have not been fully utilized and popular tourists could not pay enough attention on cultural heritages.

3) Social relation system significantly affects the entire perception of harmonious tourism environment ( 0.29 , $p=0.000$ ). It was found that the average score of social relation system is the lowest in three harmonious relation systems from the surveys, which indicates that tourists are not satisfied with the relationships among different stakeholders in "8 mountains". Because of the significance of the harmonious condition of stakeholders, it is very necessary to protect the legal rights and interests of local residents, alleviate the relation between residents and developers, hosts and guests, make tourism service more humanized, improve tourism merchant market and social security, as well as control the density of tourists.

4) Entire perception of harmonious tourism environment significantly and directly affects the tourists' loyalty $(1.15, p=0.000)$. Because of the very large coefficient (more than 1), in order to increases the tourists' satisfaction and loyalty degree, vigorously constructing the destination's harmonious tourism environment seems very fatal and crucial. We also can find that the tourists' recommendation intention is higher than revisit intention, so it is necessary to diversify the contemporary tourism products' structure, deepen the tourism products' cultural connotation, and make the tourists not visit only one time.

\section{Conclusion}

In all of the world heritages in China, the 8 mountaintype world cultural heritages are elites, because they represent the Chinese cultural spirits and nation's identity, as well as are the most famous tourist destinations, so the construction of harmonious tourism environment in "8 mountains" is very essential. In view of the very high positive coefficient of the entire perception of harmonious tourism environment to tourists' loyalty, we can conclude that harmonious tourism environment construction plays an essential role in enhancing the destination's competitiveness. Tourists now are satisfied with the natural ecosystem, which also most greatly affects the entire perception of harmonious tourism environment, thus it is necessary to maintain the harmony in natural ecosystem. Tourists' satisfaction on cultural ecosystem is relatively high, but the coefficient of cultural ecosystem to entire perception of harmonious tourism environment is relatively small, which indicates the defects exist in cultural tourism products and the low attention from tourists. Cultural heritages have very broad and deep cultural connotation, so it seems crucial for tourism developers to take more actions to diversify cultural tourism products and activities, broaden and deepen their cultural connotation, improve tourism demonstration and interpretation, as well as enhance cultural heritage education to tourists. The lowest satisfaction occurs in social relation system, shows the great flaw in the relationships among stakeholders in tourism developing process. Because research also shows the significant effect of social relation system to the perception of tourism environment, so it is very necessary and important to reform the management constitution, especially the interest distribution mechanism, protect local residents' legal rights and profits and enhance their participation intention in tourism development, eliminate the conflicts among stakeholders, finally construct a harmonious mechanism among residents, tourists and developers. There are still some drawbacks in this research, for instance, the samples inclined to select more young people, the quantity of questionnaires are not enough to make a comparative analysis among " 8 mountains" etc, and some improvements are needed in future study.

\section{Acknowledgements}

This research was supported by Fund Project of National Social Science in China (Grant No. 07BJY136). 


\section{REFERENCES}

[1] P. Murphy, M. P. Pritchard and B. Smith, "The Destination Product and Its Impact on Traveler Perceptions," Tourism Management, Vol. 21, No. 1, 2000, pp. 43-52. doi:10.1016/S0261-5177(99)00080-1

[2] M. G. Gallarza and I. G. Saura, "Value Dimensions, Perceived Value, Satisfaction and Loyalty: An Investigation of University Students' Travel Behavior," Tourism Management, Vol. 27, No. 3, 2006, pp. 437-452. doi:10.1016/j.tourman.2004.12.002

[3] C. Lee, Y. Yoon and S. Lee, "Investigating the Relationships among Perceived Value, Satisfaction, and Recommendations: The Case of the Korean DMZ," Tourism Management, Vol. 28, No. 1, 2007, pp. 204-214. doi:10.1016/j.tourman.2005.12.017

[4] C. Y. Shi, J. Zhang and H. M. You, "Structural Equation Model for tourism Destination Competitiveness from Tourists' Perception Perspectives," Geographical Research, Vol. 27, No. 3, 2008, pp. 703-714.

[5] Y. L. Huang and Z. F. Huang, "A Study on the Structural Equation Model and Its Application to Tourist Perception for Agri-Tourism Destinations: Taking Southwest Minor- ity Areas as an Example," Geographical Research, Vol. 27, No. 6, 2008, pp. 1455-1465.

[6] Y. Yoon and M. Uysal, "An Examination of the Effects of Motivation and Satisfaction on Destination Loyalty: A Structural Model,” Tourism Management, Vol. 26, No. 1, 2005, pp. 45-56. doi:10.1016/j.tourman.2003.08.016

[7] W. Zhang, J. W. Wang and H. Zhang, "Study on the Construction of Harmonious Tourism Environment for Mountain-Type World Cultural Heritages of China," Wuhan University Journal (Philosophy \& Social Sciences), No. 2, 2008, pp. 278-282.

[8] M. Opperman, “Tourism Destination Loyalty,” Journal of Travel Research, Vol. 39, No. 1, 2000, pp. 78-84. doi:10.1177/004728750003900110

[9] J. M. Fang, "An Empirical Study on the Incentive Influencing the Response Rate of the Web-Based Survey," Management Review, Vol. 18, No. 2, 2006, pp. 13-17.

[10] G. H. Chen and Y. S. Huang, "Influencing Factors on Tourists' Revisit Decision-Making: A Web-Based Empirical Study,” Tourism Tribune, Vol. 23, No. 1, 2008, pp. 69-74. 